\title{
E -Waste: Characterization and Disposal through Solid State Route
}

\author{
${ }^{1}$ Engineering Services Group, India \\ ${ }^{2}$ Analytical Chemistry Division, India \\ ${ }^{3}$ Research Reactor Services Division Bhabha Atomic Research Centre, India \\ ${ }^{4}$ Radiation and Photochemistry Division, India \\ ${ }^{5}$ Waste Management Division, India \\ ${ }^{6}$ Homi Bhabha National Institute, Bhabha Atomic Research Centre, India
}

Mishra $\mathrm{H}^{1}$, Naina Raje ${ }^{2 *}$, Arihant Jain ${ }^{3}$, Awadhesh Kumar ${ }^{4}$, A S Pente ${ }^{5}$, A P Tiwari ${ }^{6}$ and DN Badodkar ${ }^{6}$

Submission: December 12, 2019; Published: January 03, 2020

*Corresponding author: Naina Raje, Analytical Chemistry Division, BARC, Mumbai-400 085, India

\begin{abstract}
Present work demonstrates the PCB waste characterization using solid state route. Microwave and resistive heating have been used for heating the PCB waste sample and inter-comparison studies have been carried out in order to understand the nature of volatiles and residue obtained during the two different heating processes. GC -MS was used to analyze the volatiles, collected during microwave heating and shows the presence of $\mathrm{CO}_{2}$ as major volatile. Simultaneous TG -DTA -EGA (FTIR) was used in air and inert atmospheres for online analysis of volatiles where $\mathrm{CO}_{2}$ was observed as major volatile in inert atmosphere along with moisture while CO evolution was also confirmed as major evolved gas along with $\mathrm{CO}_{2}$ and moisture in air atmosphere. SEM -EDS was used to explore the surface morphology changes during different types of heating and effect of heating on the presence of various metals in the residue with respect to that of in the unheated sample. Presence of Pb has been confirmed in microwave heated PCB sample at $350{ }^{\circ} \mathrm{C}$ while it could not be seen in the resistively heated sample to $390{ }^{\circ} \mathrm{C}$. Original sample showed $\mathrm{Pb}$ and $\mathrm{Sn}$ as major constituents while residue showed $\mathrm{Al}, \mathrm{Ca}, \mathrm{Mg}, \mathrm{Ba}, \mathrm{Si}, \mathrm{Cu}$ and $\mathrm{Br}$ as major elements present. Presence of $\mathrm{Br}$ could not be seen in resistively heated sample. Formation of $\mathrm{Cu}$-Sn alloy in the residue has been confirmed through SEM - EDS mapping
\end{abstract}

Keywords: E-waste characterization; PCB; TG/DTA/EGA; SEM/EDS; GC/MS

\section{Introduction}

The rapid growth of technology, especially in the field of electronics and instrumentation and upgradation of electronic gadgets due to technological advancements in terms of providing better features at reasonable cost have led to the high rate of obsolescence in the electronic industry. Electronic industrial development has certainly provided a better life to humanity but also resulted in one of the fastest growing waste streams in the world which consists of the obsolete electrical and electronic products [1]. The generation of e-waste and its recycling needs to be addressed in India to deal with the dangerous impact of toxic ingredients on the environment and human beings [2]. Recyclers and dismantlers are explicitly dumping residual ash of e-waste generated from crude recycling processes. Apart from human exposure, the black ash powder is also affecting aquatic and terrestrial ecosystems of the region [3]. Hence, there is an immediate need to formulate an appropriate strategy to reduce e-waste pollution. The current recycling practices of e-waste in
India need critical review and require an environment friendly scientific technology for its recycling and management [4]. Printed Circuit Board (PCB) is an essential component of almost all electronic and electrical equipment's such as computers, televisions etc. and it is a major constituent of the obsolete and discarded electronic scrap. It is a heterogeneous mixture of organic material, metals and glass fiber and accounts for approximately $30 \%$ of the total e-scrap generated [5]. However, the major concern is not due to their increasing volume but is due to their complex composition and compositional variation which makes the separation and recycling more challenging. These difficulties explain the low average recycling rate which has been reported globally and represents about $15 \%$ of the total fraction of e-waste globally in 2005 [6]. But the serious pollution may be expected to get generated if PCBs are not properly disposed off as the flame retardants present therein may cause the formation of toxic compounds like polybrominated dibenzo-p-dioxins (PBDDs) 
or polybrominated dibenzofurans (PBDFs). Additionally, the toxic metal ingredients like lead and cadmium may enter the aquatic or terrestrial ecosystems, which has resulted in the elevation of blood lead and cadmium levels of children in some typical neighborhoods like Guiyu of China [7-11].

The traditional recycling technologies like pyrometallurgy and hydrometallurgy are gradually being phased out for the PCB wastes as these were majorly meant to recover metals and now are being challenged by the decreasing concentration of precious metals in e -waste. In the current scenario, various mechanical or physical processing methods are being favored and widely used for industrial applications [12-15]. Any separation process is followed with a pre step of crushing of PCB to get the fine and homogeneous sample. The major challenge faced during crushing is because of direct and continual crushing and leading to localized heating which could result in pyrolysis and easy release the toxic substances [16]. It has been reported that thermal shock may be applied as a pretreatment method to change the interfacial impact and tensile strength and it has been proven to be a potential solution to reduce crushing difficulty [17]. Pyrolysis is the process of heat treatment to a sample in the absence of oxidizing atmosphere. Hence, during this process, the PCB sample is decomposed through gaseous release and results in the enrichment of metals in the obtained solid residue. A lot of work has been reported [18,19] where PCB samples have been pyrolyzed using resistive heating in externally heated systems like thermal analyzers, fluidized bed reactors where heat transfer takes place through external heating processes like conduction, convection or radiation. It is well known that microwave heating is selective for different materials and relies on internal and volumetric heating process for heat transfer. It has been observed that because of the selective characteristic, the microwave induced pyrolysis may be applied in an energy efficient way for PCB waste heat treatment. Application of some strong microwave absorbers may expedite the pyrolysis process by rapid heating [20]. Current studies present the inter-comparison studies with respect to the PCB waste characterization using microwave and resistive heating in order to understand the nature of volatiles and residue obtained during the two different heating processes. PCB waste was grinded to get a homogenized and representative sample for its characterization through solid state route. The characterization techniques used are simultaneous TG-DTA-EGA (FTIR), SEM-EDS and GC-MS. An attempt has been made to compare the benefits of microwave heating over resistive heating in order to apply solid state route as the methodology for e - waste disposal.

\section{Material and Methods}

Experiments have been carried out using Netzsch Thermobalance (Model No.: STA 409 PC Luxx) coupled to Bruker FTIR system (Model No.: Tensor 27) via a heated Teflon capillary (1m long, $2 \mathrm{~mm}$ i.d.). In this work Pt vs. Pt-10\% Rh thermocouples were used as temperature and differential temperature sensors. Recrystallised alumina sample holders were used as sample and reference holders. TG-DTA data analysis was done using Proteus software from Netzsch. FTIR system used for the identification of IR absorbance in the mid IR region $\left(400-4000 \mathrm{~cm}^{-1}\right)$ is equipped with liquid nitrogen cooled MCT detector and low-volume gas cell $(8.7 \mathrm{~mL})$ with a $123 \mathrm{~mm}$ path length and $\mathrm{KBr}$ windows. The adapter head of thermobalance, transferline and sample cell were heated to a constant temperature of $2000 \mathrm{C}$ to avoid condensation of low volatile compounds. The FTIR compartment was continuously purged by high purity nitrogen and molecular sieves/silica gel were used to minimize the water and carbon dioxide background in the recorded spectra. The resolution of the collected spectra was set to $4 \mathrm{~cm}^{-1}$ and co-addition of 32 scans per spectrum with a scan speed of $20 \mathrm{kHz}$ was applied. As a consequence, spectra were recorded with a temporal resolution of about $2.5 \mathrm{~s}$, depending on integration methods. FTIR data analysis was done using Opus (version 6.0) software from Bruker. Simultaneous TG-DTA-EGA measurements were carried out individually on accurately weighed PCB waste samples (about $25 \mathrm{mg}$ ) in air and inert atmosphere using resistive heating furnace and heating from room temperature to $1200{ }^{\circ} \mathrm{C}$ at a heating rate of $100 \mathrm{C} \mathrm{min}^{-1}$. The flow rate of high purity nitrogen was maintained at $100 \mathrm{~mL} \mathrm{~min}$ ${ }^{1}$ to transport the volatile products. Nitrogen was also used as protective gas to the thermobalance at a flow rate of $20 \mathrm{~mL} \mathrm{~min}^{-1}$.

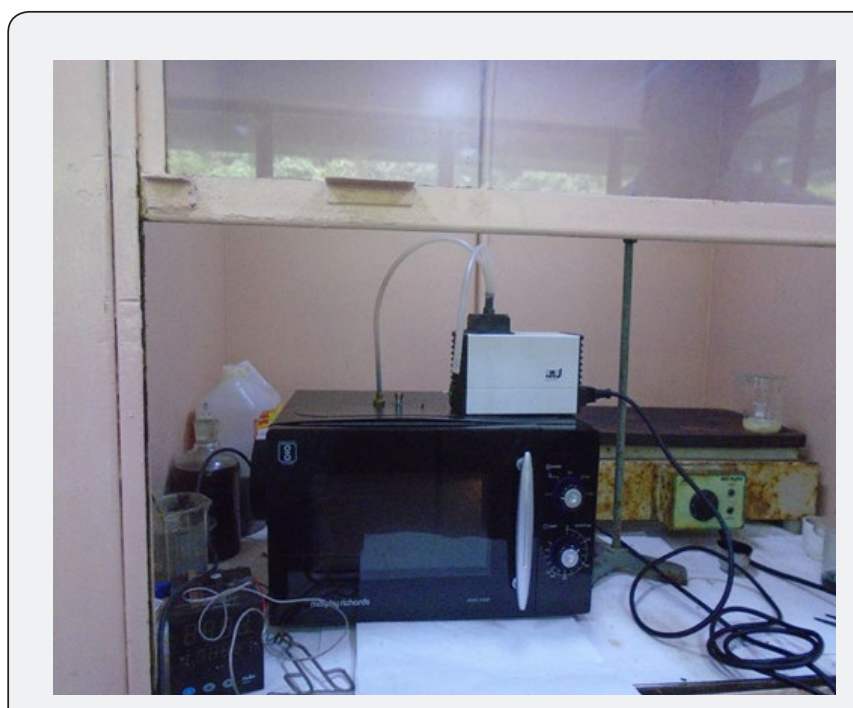

Figure 1: Microwave heating setup in fume hood.

Microwave heating experiment was carried out using Murphy Richard's microwave oven (Model No. - MWO 20MS, with oven cavity dimensions as $306 \mathrm{~mm}(\mathrm{H}) \times 306.6 \mathrm{~mm}$ (W) x $208.2 \mathrm{~mm}$ (D) and $800 \mathrm{~W}$ rated microwave power output ) on 5gram PCB sample while the inside temperature was measured as $350{ }^{\circ} \mathrm{C}$. The experiments were performed under the fume hood where 
a temperature controller with $\mathrm{K}$ type thermocouple and display unit was attached to the microwave oven to measure the inside temperature. Also, a vacuum pump (10 LPM) was used for e-waste evolved gas scrubbing and gaseous sample collection. The overall set up has shown as Figure 1. The gas samples collected during microwave heating of the PCB sample were analyzed using GCMS (Model No.- QP2010) having Quadrupole mass analyzer and Gs-BP Inowax ( $30 \mathrm{~m} \times 0.25 \mathrm{~mm} \times 0.25 \mathrm{~mm})$ and RT-QPLOT $(30 \mathrm{~m}$ $\mathrm{x} 0.32 \mathrm{~mm} \times 0.32 \mathrm{~mm}$ ) as capillary column. The programmed temperature was kept at $32-150{ }^{\circ} \mathrm{C}$ and $200{ }^{\circ} \mathrm{C}$ and the flow rate as $1.5 \mathrm{mLmin}^{-1}$ and $2.0 \mathrm{mLmin}^{-1}$. SEM -EDS analysis has been carried out on the residues obtained from PCB samples heated to $350{ }^{\circ} \mathrm{C}$ and $390{ }^{\circ} \mathrm{C}$ in resistive furnace and microwave respectively using TESCAN model VEGA3LMU (Czech Republic, EU). The measurements have been carried out after gold plating for $90 \mathrm{sec}$ $(15 \mathrm{~mA})$ in a vacuum of $4 \times 10^{-1} \mathrm{mbar}$ for which a small portion of individual sample was pasted on the graphite tape, fixed on the sample holder. The analysis has been carried out.

\section{Results and Discussions}

TG curves have been shown in Figure 2 for the PCB samples heated from room temperature to $4000 \mathrm{C}$ and $10000 \mathrm{C}$ in air / inert atmospheres. It can be seen from Figure 2 that the PCB starts decomposing around $2700 \mathrm{C}$ in both the atmospheres. The overall mass loss was found to be around 28 and $29 \%$ in inert and air atmosphere respectively but the decomposition reaction ceases by $6000 \mathrm{C}$ in air atmosphere while the degradation is seen even at $1000{ }^{\circ} \mathrm{C}$ in inert atmosphere. The observed mass loss data $(28$ $-29 \%)$ for PCB matches well with the reported data (27-30\%) of other researchers [5,21]. The presence of free carbon is suggested due to the decomposition of organic compounds which leads to exothermic reaction (Figure 3 ) in the temperature region of 420 $-590{ }^{\circ} \mathrm{C}$ in air atmosphere due to the oxidation of carbon and thus resulting in the stable product by $600{ }^{\circ} \mathrm{C}$ in air environment. Also, it can be seen from Figure 2 that mass loss at $650{ }^{\circ} \mathrm{C}$ is $17.8 \%$ while it is $16.8 \%$ at $930{ }^{\circ} \mathrm{C}$ in air which suggests the metal oxidation in the residue above $650{ }^{\circ} \mathrm{C}$. This process of oxidation has been confirmed by the exothermic peak in the temperature region of 650-700 ${ }^{\circ} \mathrm{C}$ on DTA curve recorded for air atmosphere as shown in Figure 2. The heat effects can clearly be seen in Figure 3, depicting the DTA curves in different atmospheres. DTA curve recorded in inert atmosphere shows the endothermic heat effects (320 -525 ${ }^{\circ} \mathrm{C}, 525-795{ }^{\circ} \mathrm{C}$ ) due to the pyrolytic degradation of compounds as the prominent process. It should be noted that depending on the environment, the decomposition mechanism might be different but environmental conditions are not contributing significantly on the overall thermal decomposition of the compound as total mass loss difference is only $1 \%$ in the two environments. Simultaneously recorded Gram Schmidt curves are given in Figure 4 where we can see that PCB decomposes in four major steps in both the environments. The evolved gas analysis for air and inert atmospheres can be seen in Figure 5 \& 6 respectively which depict the Gram Schmidt curve along with the corresponding extracted FTIR spectra. The first evolution of gases is seen at $282^{\circ} \mathrm{C}$ corresponding to $\mathrm{CO}_{2}$ in air while first notecible evolution of gases was observed at $379^{\circ} \mathrm{C}$ in inert atmosphere having the wave numbers $\sim 750,1174,1261$ and $3643 \mathrm{~cm}^{-1}$ which could not be identified as a specific volatile compound / gas but suggests the presence of alcohols as volatiles. The presence of $1174 \& 1261 \mathrm{~cm}$ ${ }^{1}$ may correspond to $\mathrm{C}-\mathrm{O}$ strech and $3643 \mathrm{~cm}^{-1}$ to $\mathrm{O}-\mathrm{H}$ streching vibrations in alcohols [22]. Also, the presence of wavenumber $\sim 750 \mathrm{~cm}^{-1}$ may be because of $\mathrm{C}-\mathrm{X}$ streching vibrations where $\mathrm{X}$ represents the halides like $\mathrm{Cl}$ or $\mathrm{Br}$ and hence suggests the presence of alkyl halides [23]. The nature of evolved gases is almost similar in both the environments except the presence of carbon monooxide which was observed as major evolving gas at $480{ }^{\circ} \mathrm{C}$ in air besides the presence of $\mathrm{H}_{2} \mathrm{O}, \mathrm{CO}_{2}$ and free hydroxyl group. The presence of $\mathrm{H}_{2} \mathrm{O}$ and $\mathrm{CO}_{2}$ has been confirmed by the presence of $\mathrm{H}-\mathrm{O}-\mathrm{H}$ and $\mathrm{O}-\mathrm{C}-\mathrm{O}$ bending vibrations at $1530 \mathrm{~cm}^{-1}$ and $660 \mathrm{~cm}^{-1}$ respectively and asymmetric streching vibrations for $\mathrm{H}_{2} \mathrm{O}$ and $\mathrm{CO}_{2}$ at $3650 \mathrm{~cm}^{-1}$ and $2354 \mathrm{~cm}^{-1}$ respectively [24]. The presence of $\mathrm{CO}$ at $480{ }^{\circ} \mathrm{C}$ was confirmed in air atmosphere through the $\mathrm{C}$ $=0$ streching at $2140 \mathrm{~cm}^{-1}$ [25]. Long and coworkers [19] also reported the presence of $\mathrm{CO}$ as major evolved gas at $500{ }^{\circ} \mathrm{C}$ during microwave heating besides the presence of $\mathrm{CO}_{2}$ as major evolved gas component and suggested that it may be due to decomposition of epoxy group and calcium carbonate fillers in the polymer. We could not observe the presence of $\mathrm{CO}$ during microwave heating as the temperature was well below $500{ }^{\circ} \mathrm{C}$. The presence of terminally bound hydroxyl groups at $480^{\circ} \mathrm{C}$ is being suggested due to the presence of $3730 \mathrm{~cm}^{-1}$. Finnie and coworkers have reported [26] two types of coordinated $\mathrm{H}_{2} \mathrm{O}$ and both terminally bound and bridging hydroxyl groups have been identified by the temperature-dependent behavior of their corresponding $\mathrm{O}-\mathrm{H}$ stretching modes and the terminally bound hydroxyls have been identified as $\left.(\mathrm{v}(\mathrm{OH})) 3730 \mathrm{~cm}^{-1}\right)$, Beyond $480^{\circ} \mathrm{C}$ only $\mathrm{CO}_{2}$ evolution was observed in both the environments. We can summarize that during resistive heating $\mathrm{H}_{2} \mathrm{O}, \mathrm{CO}_{2}$, $\mathrm{CO}$, free hydroxyl were the major evolved gases up to $480^{\circ} \mathrm{C}$ in air and beyond that $\mathrm{CO}_{2}$ was the only evolved gas. Presence of alkyl halides and alcohol is being suggested as minor volatiles below $400^{\circ} \mathrm{C}$. The evolved gases were collected and analyzed using GC-MS for the PCB sample which was subjected to microwave heating and $\mathrm{CO}_{2}$ was found as major volatile while acetone, acetylene and oxetane were identified as minor volatile components besides one unidentified component. Presence of these volatile components have been confirmed on the basis of $\mathrm{m} / \mathrm{e}$ ratio and retention time and matching with the standard mass spectra library. Mass spectra can be seen from Figure 7-10 are corresponding to the observed mass spectra of various gases present in the sample. The observed retention times are as $\mathrm{CO}_{2}$ (2.35 min.), acetylene (4.13min.), acetone (2.35 min.) and oxetane ( $8.45 \mathrm{~min}$.). 


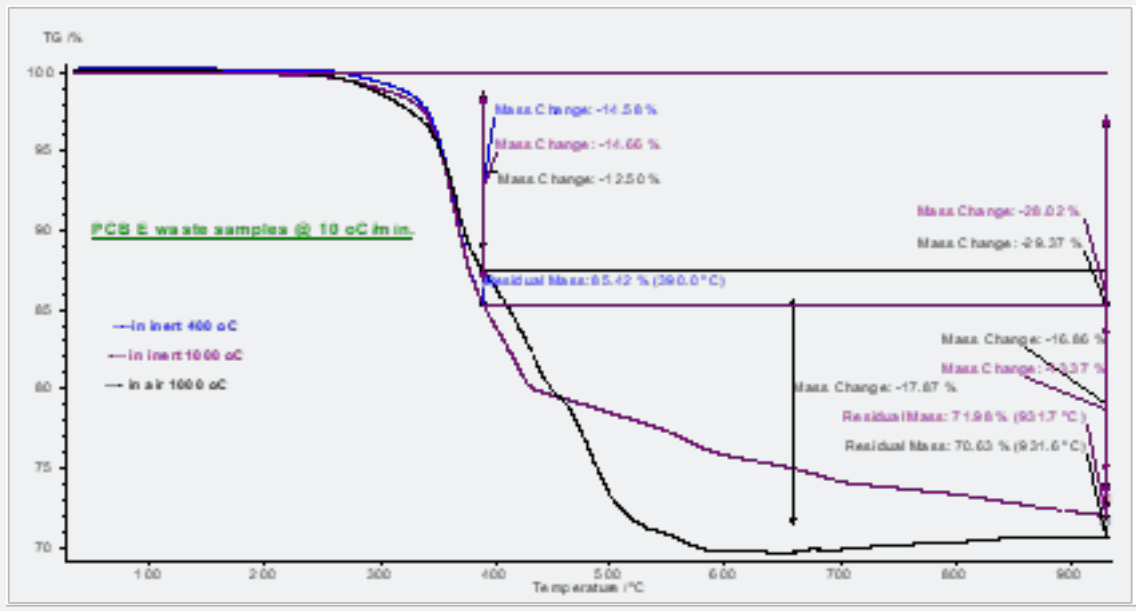

Figure 2: TG curves in air and inert atmospheres.

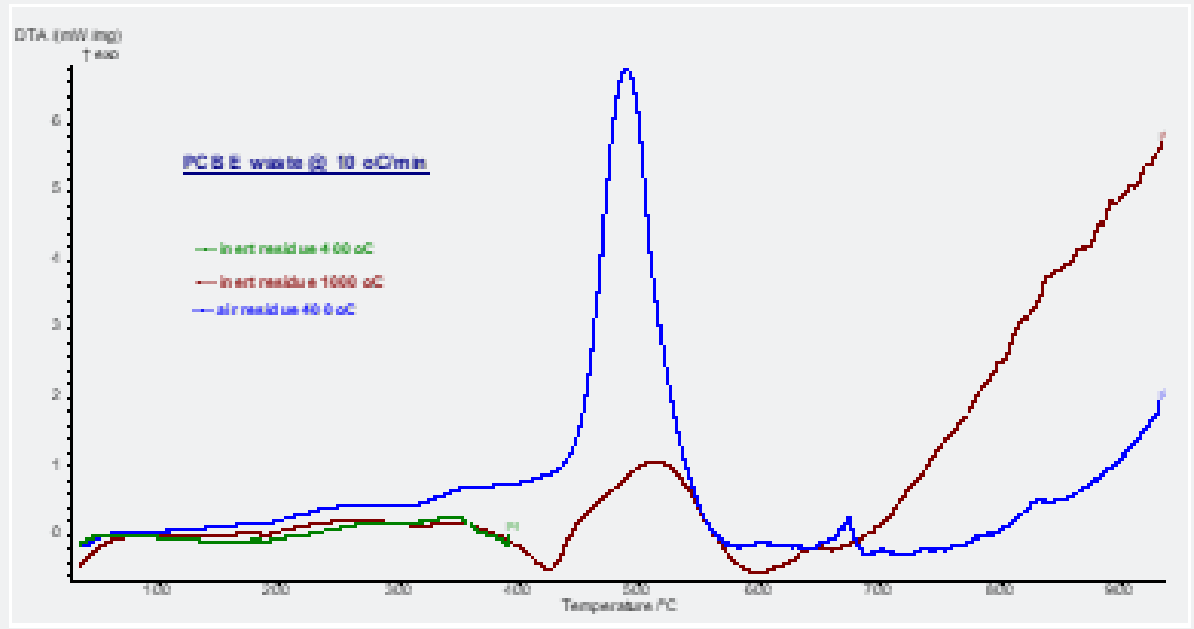

Figure 3: Simultaneously recorded DTA curves in air and inert atmospheres

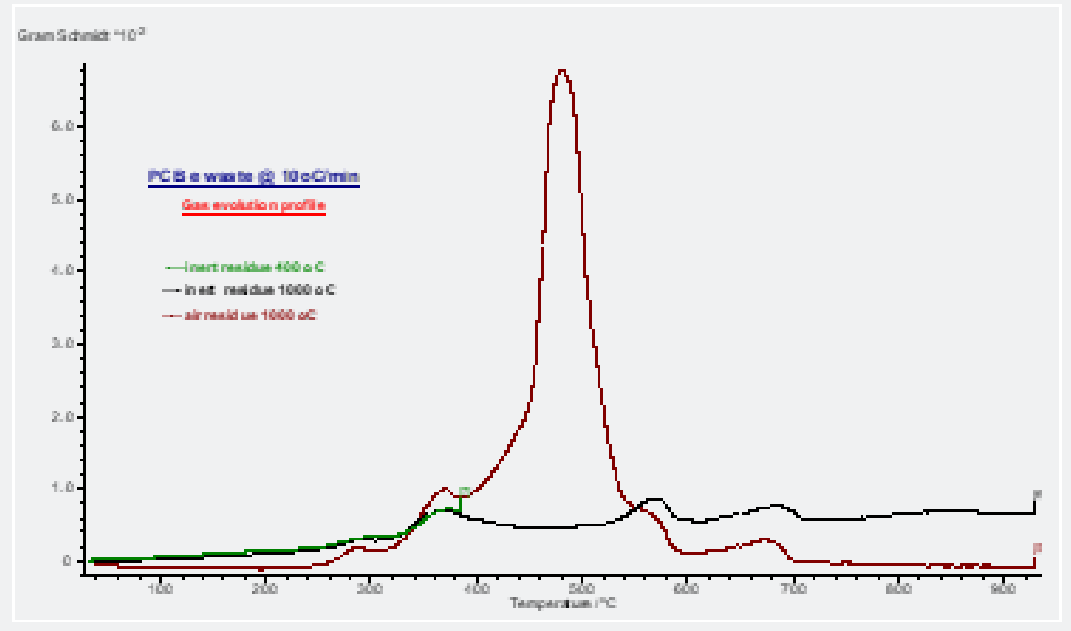

Figure 4: Simultaneously recorded Gram Schmidt curves in air and inert atmospheres. 

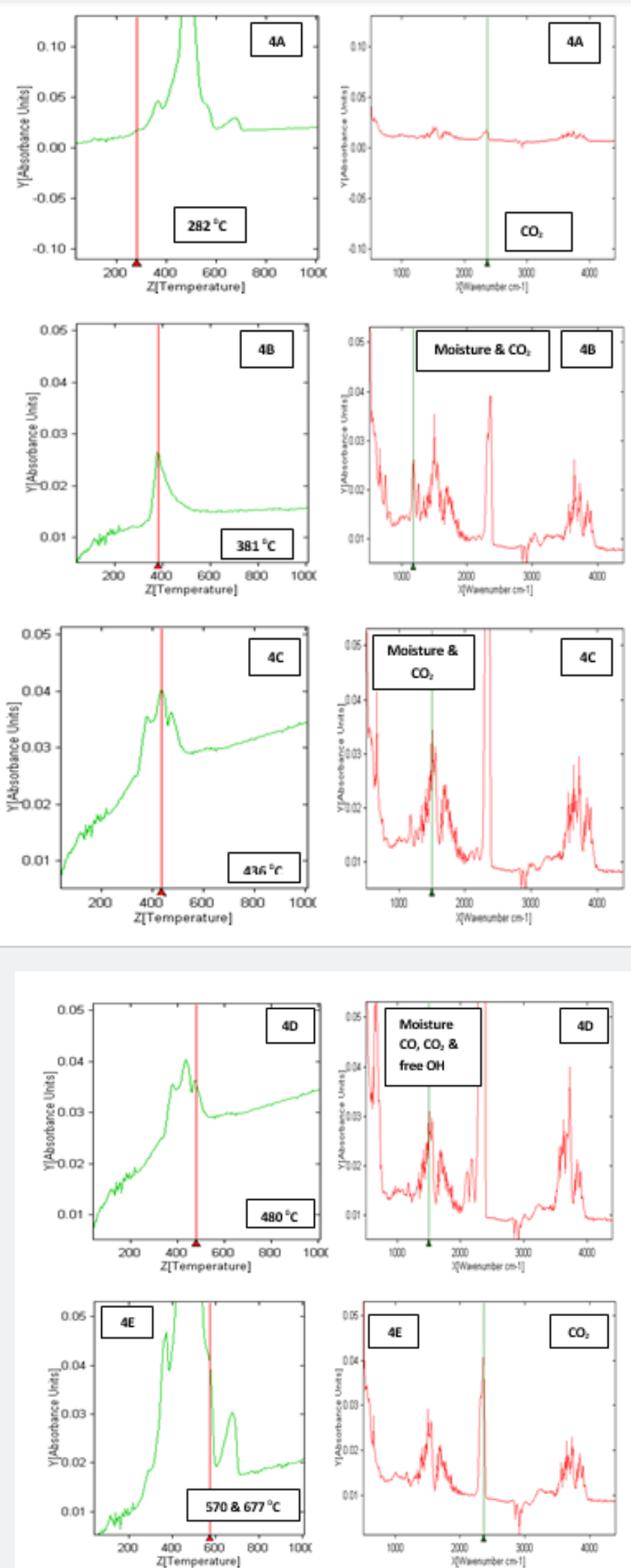

Figure 5: TG curves in air and inert atmospheres. 

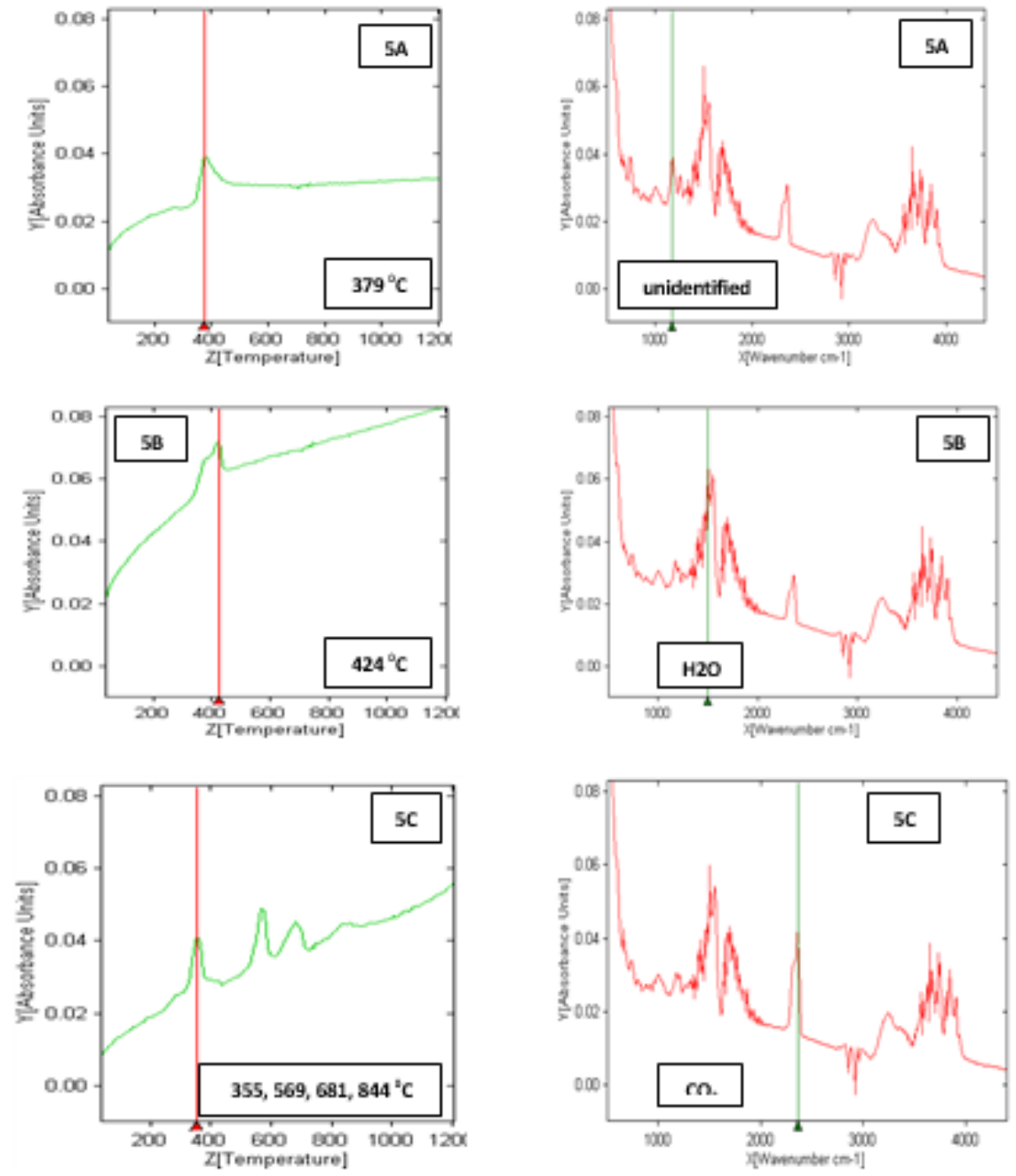

Figure 6: Simultaneously recorded Gram Schmidt curves with corresponding extracted FTIR spectra in inert atmosphere..

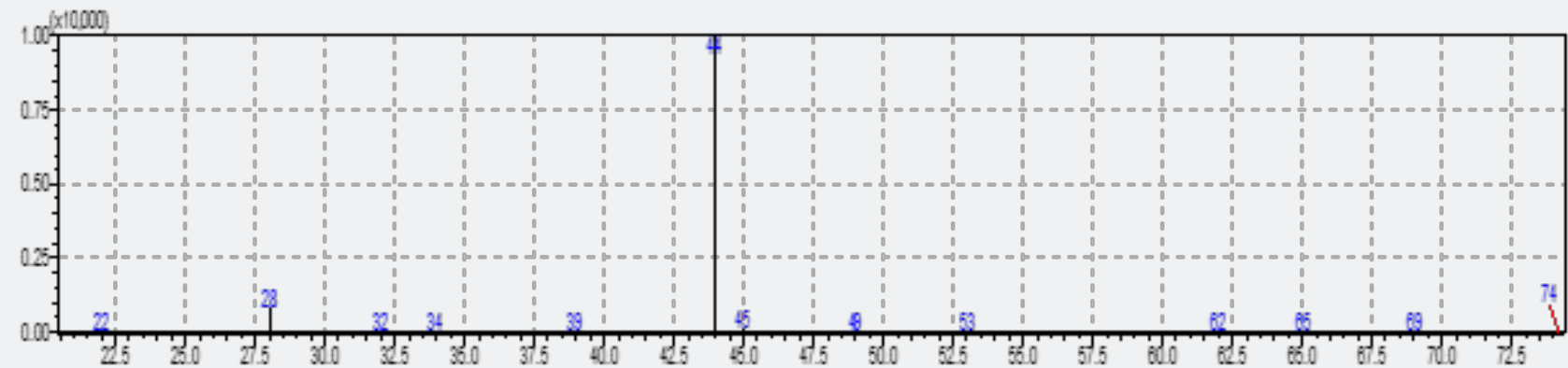

Figure 7: Mass specta of evolved CO2 (2.35min) 


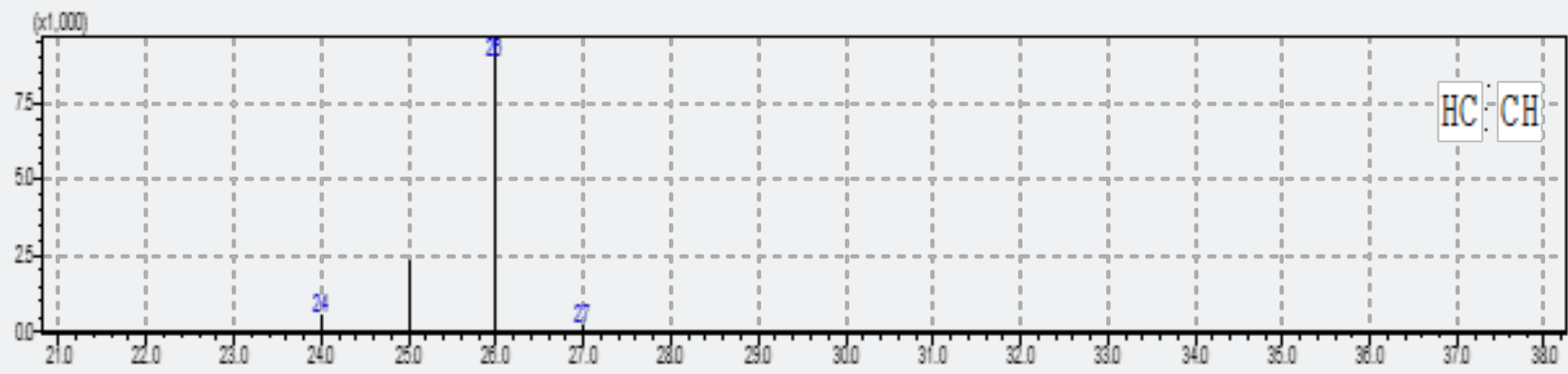

Figure 8: Mass specta of evolved Acetylene (4.13min).

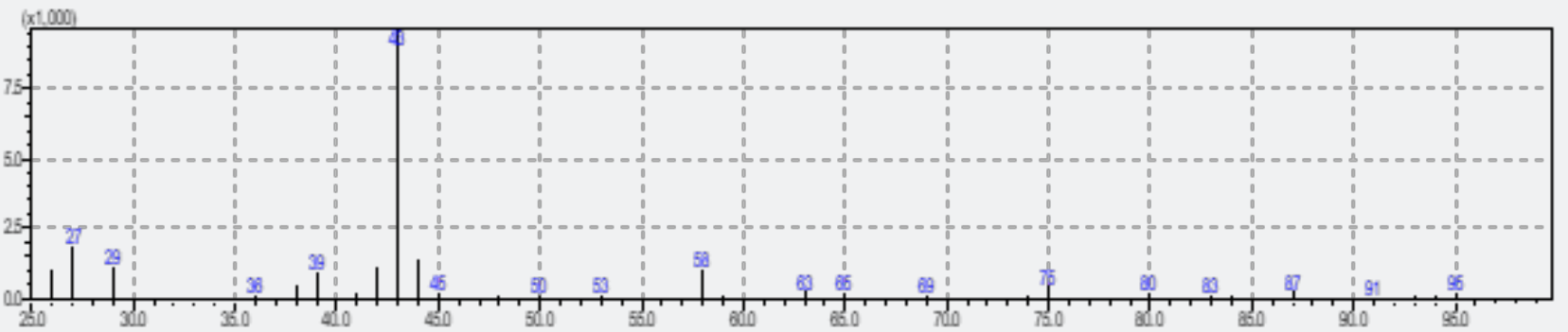

Figure 9: Mass specta of evolved Acetone (2.15min)..

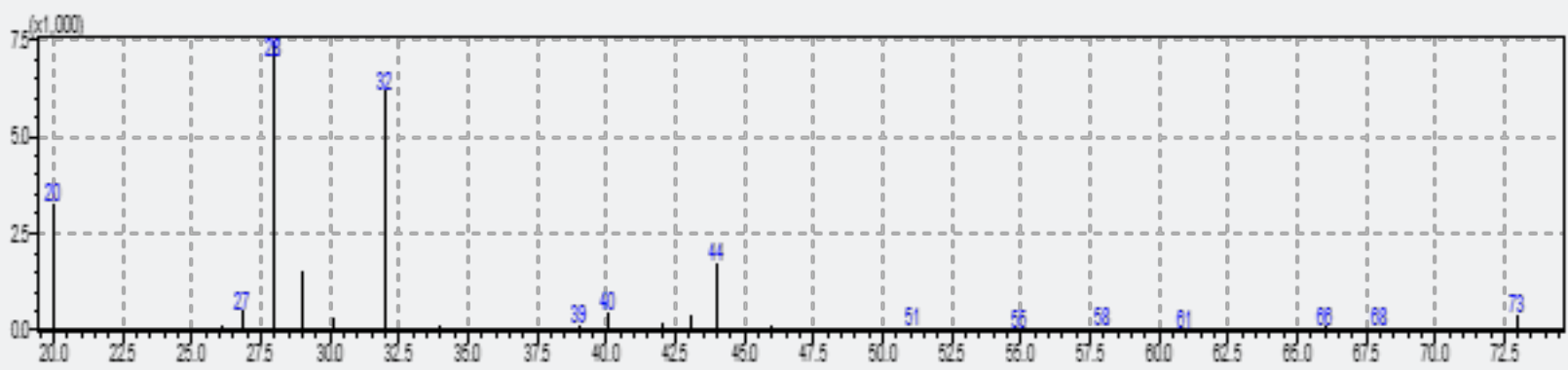

Figure 10: Mass specta of evolved oxetane (8.45min).

SEM-EDS analysis was carried out on the PCB samples on the resistively $\left(390{ }^{\circ} \mathrm{C}\right)$ and microwave $\left(350{ }^{\circ} \mathrm{C}\right)$ heated sample residues as well as on the fresh sample and can be seen in the Figure 11-13 respectively. The untreated PCB sample showed the presence of $\mathrm{Pb}$ and $\mathrm{Sn}$ as major constituents (Figure 13) while we could not see the presence of $\mathrm{Pb}$ in the resistively heated residue (Figure 11). The microwave heated residue showed the presence of $\mathrm{Pb}$ and $\mathrm{Br}$ as major constituents (Figure 12). These results match with the evolved gas analysis results where the presence of alkyl halides was suggested. Besides the presence of $\mathrm{Pb}$ and $\mathrm{Br}$, the other major constituents of the residues were found as
$\mathrm{Si}, \mathrm{Al}, \mathrm{Ca}, \mathrm{Mg}, \mathrm{Ba}, \mathrm{O}$ and $\mathrm{Sb}, \mathrm{Cl}, \mathrm{S}$ as minor constituents (Figure 11 \& 12). P Kumar and cowarkers [4] analyzed the PCB residue using solution route through ICP-OES detection and showed the presence of $\mathrm{Si}, \mathrm{Pb}, \mathrm{Sn}, \mathrm{Sb}, \mathrm{Cu}, \mathrm{Ca}, \mathrm{Al}$ as major elements. A few of the biggest advantages of solid state route characterization over solution route is the need of large amount of sample, complex time consuming dissolution processes and absence of the blank. P. Evangelopoulos and coworkers [27] have reported that the relatively high content of bromine present in PCB compared with the low concentration of chlorine and low concentration in antimony indicates that the brominated flame retardants (BFRs) 
have been used for manufacturing these PCBs. The presence of $\mathrm{Sb}$ and $\mathrm{Cl}$ as minor analytes and $\mathrm{Br}$ as major analyte can be seen in Figure 12 which indicates the similar findings as reported by $\mathrm{P}$. Evangelopoulos and suggest [27] the application of brominated flame retardants in our PCB samples. It was observed during SEM mapping that $\mathrm{Sn}$ has been retained in the residue having $\mathrm{Cu}$ which confirms the formation of $\mathrm{Cu}-\mathrm{Sn}$ alloy during microwave heat treatment. We can observe from Figure $11 \& 12$ that the surface morphology of the microwave treated residue changed a little while more damage was observed in the resistively treated residue. This difference may be partially because of temperature difference between the two types of heating and partially because of different heating process as in the case of microwave heating the heat propogates from inside out while it is the other way for resistive heating. In order to understand the exact mechanism, further investigations are required. Present studies clearly indicate that e waste can certainly not be disposed off by land filling without prior processing as it contains certain heavy and toxic metals like $\mathrm{Pb}$ which may cause hazardous impact on soil and natural water bodies. Also, evolution of gases like bromine, $\mathrm{CO}, \mathrm{CO}_{2}$ may cause environmental pollution. It has also been observed that resistive heating as well as microwave heating result in similar type of residue so it may be beneficial to use microwave heating for waste disposal due to its high efficiency in comparison to resistive heating.
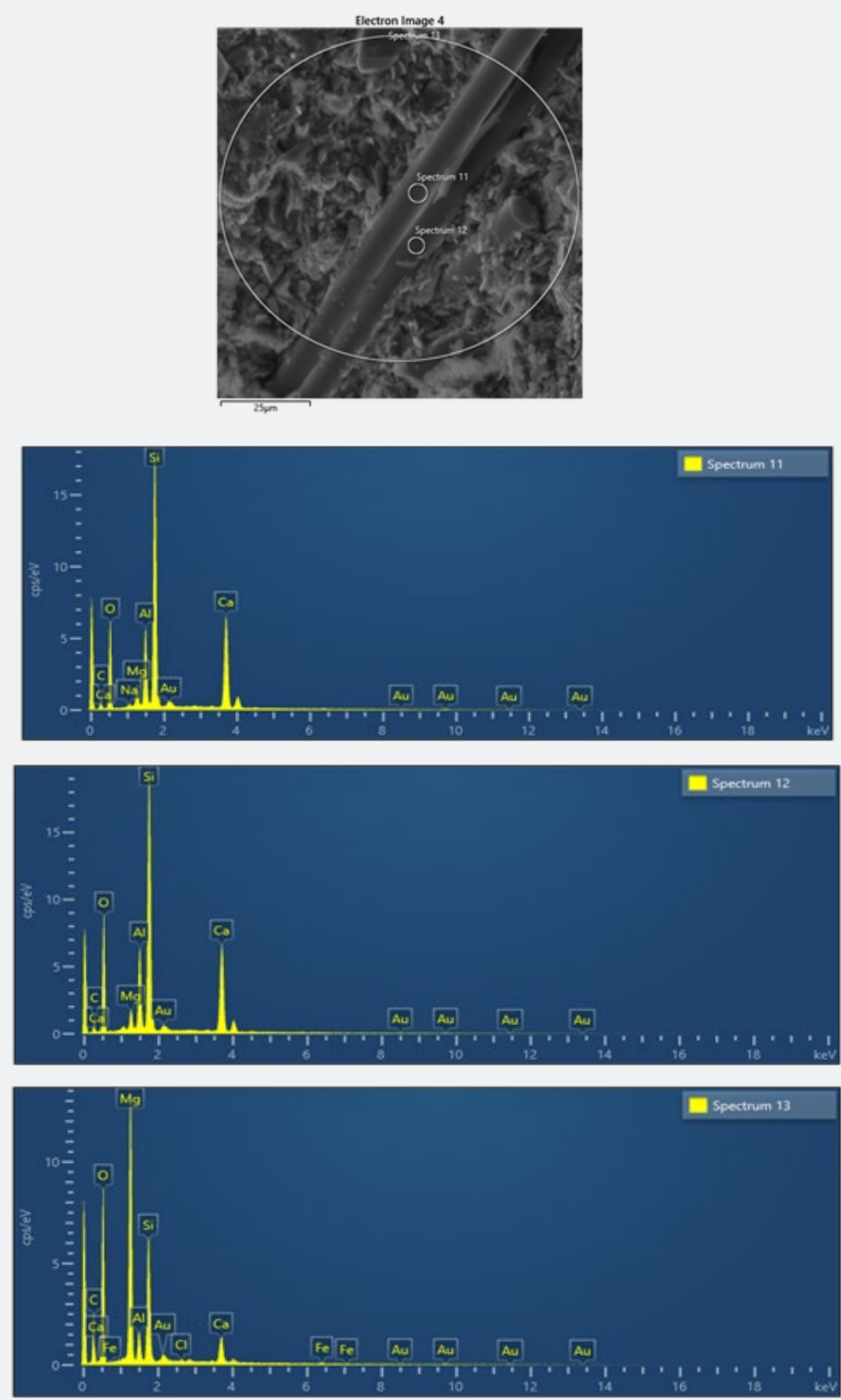

Figure 11: SEM - EDS of $\mathrm{PCB}$ residue at $3900 \mathrm{C}$ in inert atmosphere using resistive heating. 

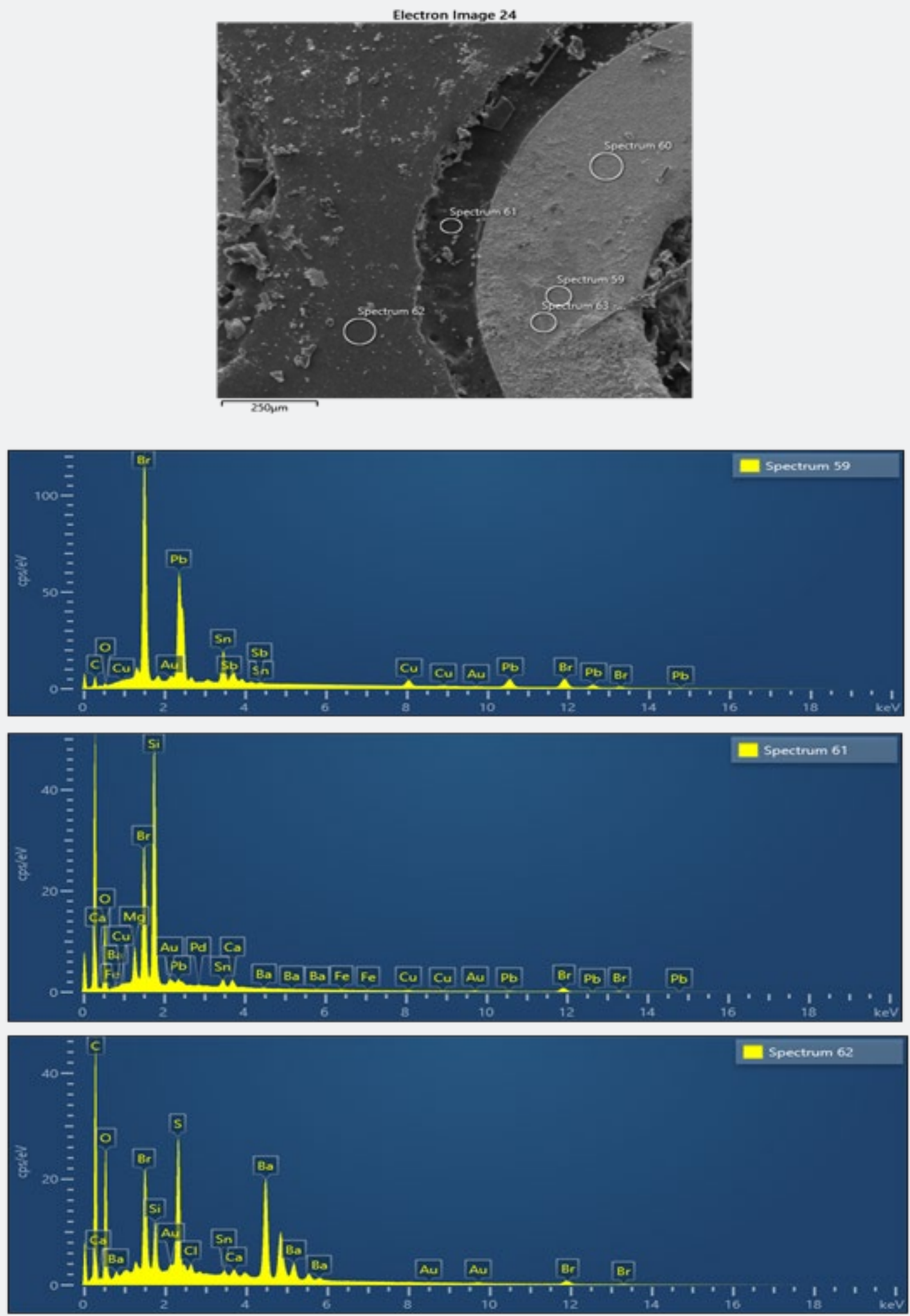

Figure 12: SEM - EDS of PCB residue at $350 \mathrm{OC}$ in inert atmosphere using microwave heating. 

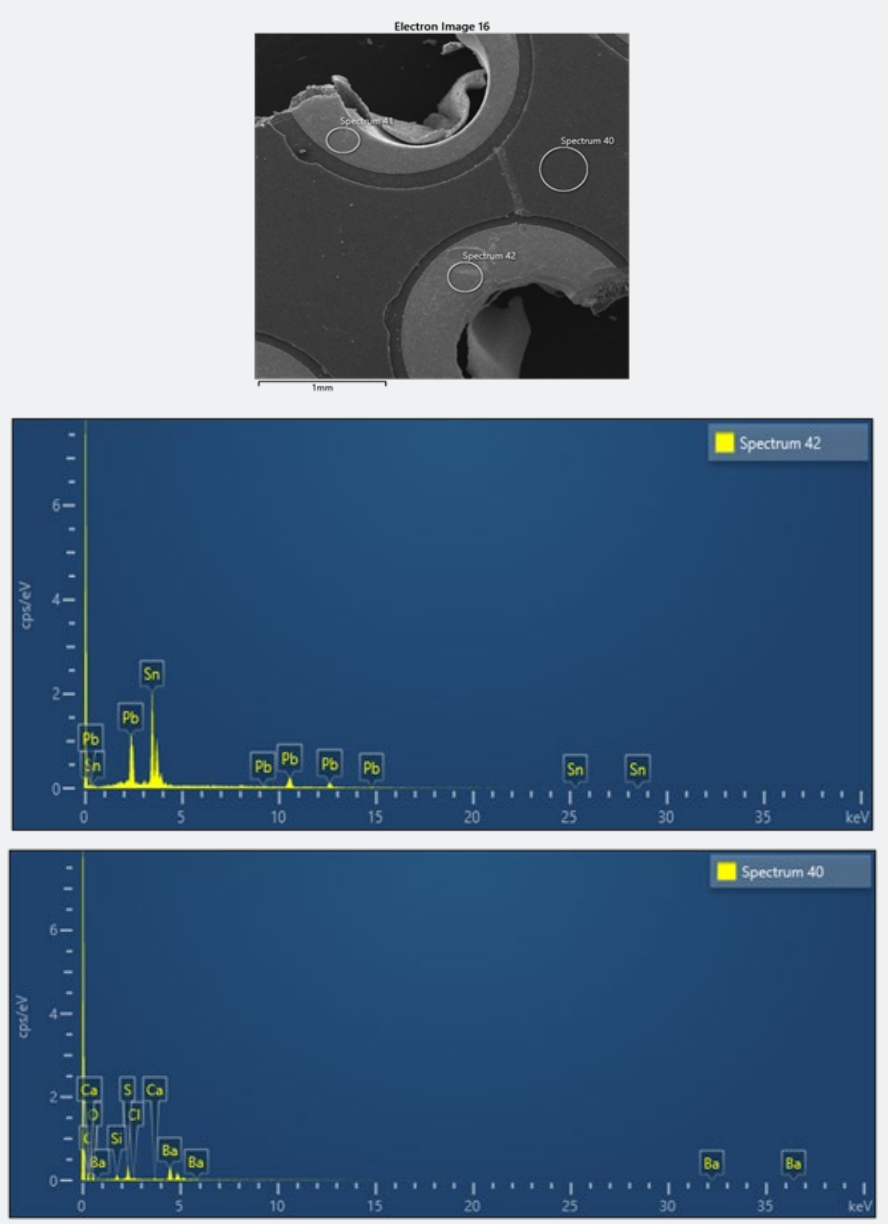

Figure 13: SEM - EDS of PCB sample.

\section{Conclusion}

Present work successfully demonstrates the application of solid-state route for the characterization of e -waste. The major constituents in the PCB residue were obtained as $\mathrm{Pb}, \mathrm{Sn}, \mathrm{Ca}, \mathrm{Cu}$, $\mathrm{Mg}$, while bromine, moisture, carbon mono and dioxide were found as major volatiles. The studies may be concluded as the preprocessing of e waste is essential before its disposal at land filling sites otherwise the presence of toxic heavy element like $\mathrm{Pb}$ may pose serious environmental implications. Also, proper care must be taken before releasing the volatiles to the environment otherwise the volatiles like bromine, carbon mono oxide etc. will result in environmental pollution. As the nature of volatiles and metallic constituents remain same in resistive and microwave heat treatment hence microwave heating may be preferred over the conventional resistive heating due to its high efficiency and less time consumption.

\section{Acknowledgement}

Authors wish to acknowledge the efforts of Dr. Archana Sharma, Head APPD and thank her for planning the experiments. We sincerely wish to thank Mr. B. Patidar, AFD, Ms. Darshana K.
Ghonge, ACD, Ms. Asmita, RPCD and Mr. Shakti Mishra, WMD for their contributions and help during this work. We would also like to extend our gratitude to Dr. H. Pal, Head, ACD and Associate Director, Chemistry Group(A) for his constant support and encouragement.

\section{References}

1. (2012) Eurostat, Waste electrical and electronic equipment (WEEE)Eurostat.

2. JK Park, L Hoerning, S Watry, T Burgett, S Matthias (2017) Effects of electronic waste on developing countries. Adv. Recycl. Waste Manage.2: 128.

3. CSE (2015) Recommendations to address the issues of informal sector involved in e-waste handling: Moradabad, Uttar Pradesh. Centre for Science and Environment, pp.1-16.

4. Pawan Kumar Bharti, RK Singh, Raju Joshi, Shambhu Thakur, AK Tyagi (2019) Metal constituents of e-waste black powder and its potential utilization, Research Communications, Current Science 116(1): 104107.

5. TR Mankhand, KK Singh, Sumit Kumar Gupta, Somnath Das (2012) Pyrolysis of printed circuit boards. International Journal of Metallurgical Engineering, 1(6): 102-107. 
6. PT Williams (2005) Waste Treatment and Disposal. (2 ${ }^{\text {nd }}$ edn), Wiley, West Sussex, England, pp. 171-244.

7. AOW Leung, WJ Luksemburg, AS Wong, MH Wong (2007) Environ Sci Technol 41(8): 2730-2737.

8. CW Schmidt (2006) Unfair trade: e-waste in Africa, Environ Health Perspect 114(a): a232-a235.

9. Huo X, Peng L, Xu X, Zheng L, Qiu B, et al. (2007) Elevated blood lead levels of children in Guiyu, an electronic waste recycling town in China. Environ Health Perspect 115(7): 1113-1117.

10. Leung A, Cai ZW, Wong MH (2006) Environmental contamination from electronic waste recycling at Guiyu, Southeast China, J. Mater. Cycles Waste Management 8(1): 21-33.

11. Wong CS, Wu SC, Duzgoren-Aydin NS, Aydin A, Wong MH (2007) Trace metal contamination of sediments in an e-waste processing village in China. Environ Pollut 145(2): 434-442.

12. Li J, Lu H, Guo J, Xu Z, Zhou Y (2007) Recycle technology for recovering resources and products from waste printed circuit boards. Environ Sci Technol 41(6): 1995-2000.

13. Li J, Xu Z, Zhou Y (2009) Application of corona discharge and electrostatic force to separate metals and nonmetals from crushed particles of waste printed circuit boards. J Hazard Mater 161: 257-262.

14. Cui J, Forssberg E (2003) Mechanical recycling of waste electric and electronic equipment: a review. J Hazard Mater B99: 243-263.

15. Eswaraiah C, Kavitha T, Vidyasagar S, Narayanan SS (2008) Classification of metals and plastics from printed circuit boards (PCB) using air classifier. Chem Eng Process 47(4): 565-576.

16. Zhao M, Li J, Yu K, Zhu F, Wen X (2006) Measurement of pyrolysis contamination during crushing of waste printed circuit board. J Tsinghua Univ 46: 1995-1998.

17. Li J, Duan H, Yu K, Wang S (2010) Interfacial and mechanical property analysis of waste printed circuit boards subject to thermal shock. J Air Waste Manage Assoc 60(2): 229A-236A.
18. Hall WJ, Williams PT (2006) Pyrolysis of brominated feedstock plastic in a fluidized bed reactor. J Anal Appl Pyrol 77: 75-82.

19. Long L, Sun S, Zhong S, Dai W, Liu J, et al. (2010) Using vacuum pyrolysis and mechanical processing for recycling waste printed circuit boards, J. Hazard. Mater. 177(1-3): 626-632.

20. Sun J, Wang W, Liu Z, Ma C (2011) Study of the transference rules for $\mathrm{Br}$ in WPCBs during Microwave-induced Pyrolysis. J Air Waste Manag Assoc 61(5): 535-542.

21. Sun J, Wang W, Liu Z, Ma C (2011) Recycling of waste printed circuit boards by microwave-induced pyrolysis and featured mechanical processing. Ind Eng Chem Res 50: 11763-11769.

22. Skoog DA, Holler FJ, Nieman TA Applications of Infrared Spectrometry, Chapter 17, Principles of Instrumental Analysis, ( $5^{\text {th }}$ edn), Saunders Golden and Harcourt College Publishers, USA, p. 410.

23.https://chem.libretexts.org/Bookshelves/Organic_Chemistry/ Map\%3A_Organic_Chemistry_\%28McMurry\%29/Chapter_12\%3A_ Structure_Determination\%3A_Mass_Spectrometry_and_Infrared Spectroscopy/12.08_Infrared_Spectra_of_Some_Common_Functional_ Groups

24. Skoog DA, Holler FJ, Nieman TA An introduction to Infrared Spectrometry. Principles of Instrumental Analysis, Chapter $16,\left(5^{\text {th }}\right.$ edn), Saunders Golden and Harcourt College Publishers, USA, pp. 388389 .

25. Gerakines PA, Schutte WA, Greenberg JM, van Dishoec EF (1995) The infrared band strengths of $\mathrm{H} 2 \mathrm{O}, \mathrm{CO}$ and $\mathrm{CO} 2$ in laboratory simulations of astrophysical ice mixtures. Astronomy and Astrophysics, astroph/9409076: 1-17.

26. Finnie KS, Cassidy JD, Bartlett JR, Woolfrey JL (2001) IR spectroscopy of surface water and hydroxyl species on nanocrystalline $\mathrm{TiO}_{2}$ films. Langmuir 17: 816-820.

27. Evangelopoulos P, Kantarelis E, Yang W (2015) Investigation of the thermal decomposition of printed circuit boards(PCBs) via thermogravimetric analysis (TGA) and analytical pyrolysis (Py-GC/ MS). Journal of Analytical and Applied Pyrolysis 115: 337-343.
Your next submission with Juniper Publishers will reach you the below assets

- Quality Editorial service

- Swift Peer Review

- Reprints availability

- E-prints Service

- Manuscript Podcast for convenient understanding

- Global attainment for your research

- Manuscript accessibility in different formats ( Pdf, E-pub, Full Text, Audio)

- Unceasing customer service

Track the below URL for one-step submission https://juniperpublishers.com/online-submission.php 